\title{
EL ASENTAMIENTO ISLÁMICO PREALMOHADE DE JEREZ DE LA FRONTERA (CÁDIZ) ${ }^{1}$
}

\section{THE PRE-ALMOHAD SETTLEMENT OF JEREZ DE LA FRONTERA (CÁDIZ)}

\author{
por \\ LAUREANO AGUILAR MOYA \\ ROSALÍA GONZÁLEZ RODRÍGUEZ \\ FRANCISCO BARRIONUEVO CONTRERAS
}

RESUMEN La ciudad de Jerez de la Frontera, bastante conocida en el período almohade, ha sido hasta hace muy poco tiempo totalmente desconocida en su etapa medieval previa, hasta el punto de llegar a dudarse de la existencia de un núcleo de población anterior a mediados del siglo XII. Sin embargo, las investigaciones más recientes están aportando datos novedosos sobre un asentamiento previo a la segunda mitad del siglo XII. Estas aportaciones amplían el conocimiento de la etapa islámica prealmohade, período sobre el que las investigaciones arqueológicas no abundan en el suroeste peninsular.

\begin{abstract}
The city of Jerez, despite its almohad period being well known, has remained until very recent years completely unknown as far as its previous medieval stage is concerned. This is to such an extent, that its existence as an inhabited settlement before middle $12^{\text {th }}$ century has been seriously questioned. Never the less, the latest investigations are providing new clues about a settlement previous to the second half of the $12^{\text {th }}$ century. This information enlarges our knowledge of its prealmohad Islamic period about which not enough archaeological research has been carried out in the southwest of the peninsula.
\end{abstract}

La ciudad de Jerez fue durante el período almohade el núcleo urbano más destacado entre Sevilla y el Estrecho de Gibraltar. Las fuentes documentales, las estructuras arquitectónicas conservadas, así como los datos arqueológicos aportados por recientes investigaciones, permiten una aproximación a la última etapa y la más importante de la historia del Jerez islámico.

1. Este trabajo fue presentado en el II Encontro de Arqueologia do Sudoeste, celebrado en Faro en Noviembre de 1996. Debido a que las Actas de este Congreso no van a ser publicadas y considerando que sus aportaciones aún son de interés, agradecemos al Consejo de Redacción de la Revista Spal su inclusión en este número. 
No obstante, son muy pocos los datos que conocemos del Jerez islámico prealmohade y en cuanto a las fuentes escritas son escasas las citas anteriores al siglo XII.

Las primeras referencias las encontramos en Ahmad al-Razí (Leví-Provençal 1953) que escribe a mediados del siglo X: “... Jerez es reputada entre todas las villas de España y en ella se reúnen todas las ventajas terrestres y marítimas". Esta descripción, sin embargo, hay que observarla con cierta precaución, puesto que no se conoce el texto original y en el momento de la composición de la copia portuguesa (siglo XIV), Jerez era con mucho la cabecera de toda la zona.

A mediados del siglo XI al-Udri (Abid Mizal 1989) menciona en su obra geográfica la ciudad de Jerez y una alquería de Jerez.

Otra referencia para el período de taifas, aunque en una obra tardía, la tenemos en Ibn 'Idari (siglos XIII-XIV) (cit. por Viguera 1992:122), que la enumera como una de las ciudades pertenecientes a la taifa Jizruní de Arcos.

Por último, destacamos también la descripción que de la ciudad y sus caminos hace al-Idrisí (Abid Mizal 1989) en la primera mitad del siglo XII: "De Carmona a Jerez que pertenece a la cora de Siduna, hay tres etapas y de la ciudad de Sevilla a Jerez dos etapas muy largas. La ciudad de Jerez es de mediano tamaño y bien fortificada por todas sus partes, está rodeada de muchas vides, olivos e higueras, y posee abundante trigo a precios convenientes". También cita otra serie de caminos, que comunican a la ciudad con Andalucía Oriental y Occidental.

Desde el punto de vista arqueológico, los únicos datos que se tenían del Jerez anterior al siglo XII procedían de las excavaciones efectuadas en 1992 en la C/ Muro (Aguilar 1995), donde se localizaron una serie de niveles del siglo XI cortados por la cimentación de la muralla almohade.

Los conjuntos cerámicos que aquí presentamos vienen a ampliar los conocimientos del núcleo prealmohade. Estos materiales proceden de trabajos arqueológicos realizados en el interior del Alcázar y en la C/Justicia (lugar muy próximo a la $\mathrm{C} / \mathrm{Muro}$ ), coincidiendo con las dos zonas topográficamente más elevadas de la ciudad. En ambos casos se trata de pozos de vertido excavados en el terreno natural, localizados en el caso del Alcázar bajo estructuras almohades, y presentan como ventaja el tratarse de contextos perfectamente sellados.

\section{1.- C/ JUSTICIA 34}

Durante las obras de nivelación del solar para la construcción de un nuevo edificio, se localizaron diversos pozos de cronología medieval y moderna. El pozo que aquí estudiamos posee planta circular de $110 \mathrm{~cm}$ de diámetro y, en el momento de su excavación, sólo conservaba $60 \mathrm{~cm}$ de potencia, al haber sido afectado por la cimentación de la casa derribada.

Entre los materiales cerámicos recuperados anotamos como características generales la alta proporción de formas cerradas y la escasa presencia de formas vidriadas, lo que supone ya un elemento de contraste con los conjuntos almohades conocidos del propio Jerez.

Observamos un primer grupo de piezas (fig. 1;1-3) formado por jarritas de dos asas, de pastas claras bastante depuradas. Muestran forma cilíndrica con un amplio baquetón moldurado entre la unión del largo cuello y la panza. Esta última presenta una carena a media altura. Los fondos son planos o convexos. De este tipo de piezas existen varios ejemplares en los fondos del Museo de Jerez (fig. 1;6-7) procedentes algunos de ellos del cercano yacimiento de Mesas de Asta (fig. 1;7), yacimiento del que ya fue dado a conocer por L. Olmo un ejemplar con decoración bruñida (Olmo 1986b).

Los lugares donde se han localizado este tipo de cerámicas se circunscriben, hasta el momento, a zonas de las actuales provincias de Cádiz -Mesas de Asta en Jerez de la Frontera (Olmo 1986b) y Castillo de 
Doña Blanca en el Puerto de Santa María (López y otros 1988)-, Sevilla (Pérez y Tabales 1995) y Huelva -Huelva capital y Niebla (Belén y Escacena1990; Olmo 1986a)-. Recientes investigaciones centran su producción en época califal-taifa (finales del siglo X - inicios del siglo XI) (Fernández y otros 1990). Corresponde al tipo 2 de jarritas de la tipología de Retuerce y Zozaya, que lo consideran una forma excepcional, reducida a la zona de la desembocadura del Guadalquivir y Niebla, con una cronología del siglo XI (Retuerce y Zozaya 1987)

Frecuentemente presentan decoración pintada (fig. 1;1-3, 6 y 7) centrada en el cuello y en la parte superior del cuerpo, bajo el baquetón moldurado. Los motivos, pintados en rojo sobre la pasta clara, van desde los simples goterones de pintura hasta elaborados conjuntos de ondas, líneas paralelas y retículas. Es interesante el motivo de crucetas con puntos entre las aspas (fig. 1;1), que encontramos repetido en una pequeña jarrita (fig. 1;5) de cuerpo piriforme, con alto y estrecho cuello, para la que no hemos encontrado paralelos formales. Esta decoración se encuentra, a veces en pintura blanca sobre fondo rojo, en cerámicas del Sur de Portugal (Mértola, Cerro da Vila), con formas en algunos casos muy similares a éstas (Torres 1987: figs. 15-16), fechadas entre los siglos IX-XI (Matos 1987: 446; Torres y otros 1987).

La forma más representada en este conjunto es la de los jarros (fig. 2; 8-11). Aunque en su mayoría se trata de piezas fragmentadas, el ejemplar numero 11 de la figura 2 , permite su definición como jarros de una sola asa. Poseen cuello recto o ligeramente exvasado, con bordes apuntados, cuerpo estriado y fondos planos o ligeramente convexos, estando completamente ausentes los pies indicados. La decoración se circunscribe al cuello, con grandes manchas de óxido de hierro o manganeso. Este tipo es bastante bien conocido, con abundantes paralelos en todo el territorio andalusí de los siglos X y XI (p.e. Olmo 1986a).

Señalamos también la aparición de jarros de boca ancha y pico vertedor (fig. 2;12), que difieren de los característicos almohades del suroeste peninsular por la ausencia de resalte o moldura bajo el borde (Cavilla 1992), así como por el amplio desarrollo del pitorro. Su forma recuerda a los tipos portugueses fechados por Varela en los siglos VIII y IX (Varela y Varela 1995) y podría tratarse de perduraciones, como en el caso de las ollas (fig. 3;18-20) consideradas comúnmente de tradición tardo-romana (Motos 1991).

Entre las formas abiertas se encuentran lebrillos de grandes dimensiones (fig. 2;15), decorados con trazos de pintura roja y negra en el borde e interior.

Los ataifores son muy escasos y constituyen las únicas piezas con decoración vidriada (fig. 3; 16-17). Muestran bordes con engrosamiento externo de sección semicircular y trazos de manganeso bajo baño de vedrío verde o verde-melado. Las pastas, en general, son grises y bien decantadas. Aunque no conocemos el desarrollo de los fondos, sus rasgos morfológicos parecen corresponder a ataifores de tradición califal (Retuerce y Zozaya 1987: fig. 3, I-7).

Otros elementos cerámicos de interés son un arcaduz con fondo plano (fig. 3;22), y un candil de forma bitroncocónica, reborde en el perímetro del disco y piquera sencilla sin facetar (fig. 3;23), cuya cronología se sitúa en ambos casos en torno al siglo X (Fuertes y González 1993).

Anotamos, por último, la presencia de un posible tambor (fig. 3;21) (Roselló 1991: 177) y una pequeña cucharilla de bronce (fig. 3;24) con funciones quirúrgicas o cosméticas (Azuer 1989).

\section{2.- ALCÁZAR. INTERIOR DEL PALACIO DE VILLAVICENCIO}

En los trabajos arqueológicos efectuados en los años 1990-91 en el interior del palacio de Villavicencio con motivo de las obras de restauración del mismo, fueron localizadas bajo niveles almohades diversas estructuras subterráneas a modo de pozo, algunas de las cuales, pertenecientes a época prealmohade, exponemos a continuación. 


\section{- Pozos 5 y 7}

Presentan materiales muy similares, por lo que se afronta su estudio en conjunto.

De nuevo encontramos jarras cilíndricas molduradas, con el mismo esquema morfológico que las descritas anteriormente (fig. 4; 27, 29-30). Sin embargo, no presentan decoración pintada y en ellas se aprecia una carena menos marcada y el baquetón con pocas o ninguna acanaladura, rasgos que las hacen más similares a las registradas en Niebla (Olmo 1986a) y que acaso señalen una cierta evolución cronológica.

Dentro de esta misma línea de evolución cronológica son numerosas, aunque muy fragmentadas, las piezas decoradas con la técnica de verde y manganeso, en especial en el pozo 5. Junto a ellas aparece un ataifor con decoración epigráfica en manganeso bajo cubierta vítrea plumbífera (fig. 4;28). A estas técnicas se les viene asignando una cronología de fines del siglo X y sobre todo siglo XI ( Valdés 1986; Gómez 1993; Torres 1987: fig 38).

La cerámica común presenta características similares a las descritas en el conjunto de $\mathrm{C} /$ Justicia: jarros de labio biselado y fondos de tendencia plana (fig. $4 ; 31$ ), ollas de cocina de labio vuelto (fig. 4;32-34) y candiles de cazoleta bitroncocónica y reborde en el disco (fig. 4;35). Señalamos también la presencia de un jarro de boca trilobulada (fig. 4;25), en la línea de las producciones califales, con pasta clara bien decantada, estrías en el cuello y decoración en el borde de una udja en pintura roja. Un motivo muy similar a éste aparece en una pieza procedente de las antiguas excavaciones en Mesas de Asta, fechable entre los siglos X-XI

\section{- Pozo 1}

Se caracteriza por presentar una mayor proporción de vidriados que los pozos anteriores, aunque sin llegar a los altos porcentajes característicos de la segunda mitad del siglo XII y principios del siglo XIII.

Entre los tipos cerámicos reconocidos se halla una serie de ataifores, en verde y manganeso con motivos geométricos cuadrangulares o bandas concéntricas rellenas de puntos (fig. 5;36 y 37), de tipología y decoración propias del siglo XI (Kirchner 1986; Gómez 1993). Junto a ellos aparecen ataifores y cuencos vidriados con círculos secantes en manganeso (fig. 5;38 y 39), que responden a formas que se desarrollan entre el siglo X y la primera mitad del XII (Torres 1987).

Es significativa y novedosa con respecto a los conjuntos anteriores la presencia de fragmentos de cerámica decoradas con cuerda seca parcial, como una jarrita que desarrolla el tema del cordón de la eternidad (fig. 5;40) y cuyos paralelos formales los encontramos en tipos fechados en el siglo X (Matos 1987: $445 \mathrm{n}^{\circ}$ 0146). También en cuerda seca parcial se registra un candil de cazoleta lenticular (fig. 5;43), con un motivo decorativo idéntico a un candil de Niebla de finales del siglo X-XI (Fernández y otros 1990). A estos ejemplares hay que añadir varios fragmentos de ataifor con cuerda seca total, aunque no se ha podido discernir ni su forma ni sus motivos decorativos.

Junto a estas cerámicas, encontramos cazuelas bizcochadas con baño de engalba roja en el interior (fig. $5 ; 42$ ) $\mathrm{y}$, finalmente, arcaduces tanto de fondo plano como apuntados, presentando estos últimos la característica original de tener la base facetada (fig. $5 ; 41$ ). Piezas similares a ésta se documentan en los Baños de la Reina Mora de Sevilla (Carrasco 1987).

Como conclusión, podemos situar cronológicamente todos los materiales hasta aquí presentados entre unas fechas que oscilan, como límite superior a fines del periodo califal, e inferior a comienzos del siglo XII. 
No obstante, la comparación entre los registros de los distintos pozos permite una cierta ordenación cronológica de los mismos.

En el conjunto de la calle Justicia, la presencia casi anecdótica de cerámica vidriada, la ausencia de técnicas decorativas como el verde y manganeso o la cuerda seca, el alto porcentaje de formas cerradas y la presencia de tipos formales y decoraciones entroncadas con el mundo califal, permiten , en el estado actual de las investigaciones, situarlo en torno a la segunda mitad del siglo $\mathrm{X}$.

En los pozos 5 y 7 encontramos ya abundantes fragmentos de cerámica en verde y manganeso y formas de cerámica común con una cronología de fines del siglo X y sobre todo siglo XI.

Algo posterior consideramos el pozo 1 del alcázar, en el que ya se observa junto a cerámicas en verde y manganeso la presencia de decoraciones de cuerda seca parcial y total, así como una mayor proporción de cerámicas vidriadas.

Estas cerámicas de los siglos X y XI responden, dentro de la tendencia general de todo al-Andalus, a unos tipos bien definidos y propios del suroeste (Lafuente 1994), en los que podríamos considerar como elemento caracterizador la presencia de jarras cilíndricas molduradas. Esta "regionalización" parece ir disolviéndose a partir de la segunda mitad del siglo XI, para desaparecer casi completamente en época almohade.

\section{BIBLIOGRAFÍA}

ABID MIZAL, J (1989): Al-Idrisí: Los caminos de al-Andalus en el siglo XII, según uns al-muhay wa rawd al furay. Ed. de Jassim Abid Mizal. Consejo Superior de Investigaciones Científicas, Madrid.

AGUILAR, L. (1995): "Excavaciones arqueológicas de urgencia en C/Muro, Jerez de la Frontera (Cádiz)". Anuario Arqueológico de Andalucía, 1992, T. III: 115-119.

AZUER, R. (1989): Denia islámica. Arqueología y poblamiento. Alicante.

BELÉN, M. y ESCACENA, J.L. (1990): "Niebla (Huelva).Excavaciones junto a la Puerta de Sevilla (19781982)". Huelva Arqueológica XII: 167-305.

CARRASCO, M.J. (1987): “Avance del estudio de la cerámica hispano-musulmana procedente de los Baños de la Reina Mora (Sevilla)" II Congreso de Arqueología Medieval Española II : 529-538.

CAVILLA, F. (1992): La cerámica hispanomusulmana de Beca. Los caños de Meca, Barbate, Cádiz. Servicio de Publicaciones de la Universidad de Cádiz.

FERNÁNDEZ, S. y otros (1990): "Cerámicas hispanomusulmanas de Niebla (Huelva): resultado de los análisis químico-minerológicos". Boletín de Arqueología Medieval 4. Asociación Española de Arqueología Medieval: 237-250.

FUERTES, M.C. y GONZÁLEZ, M. (1993): “ Avance al estudio tipológico de la cerámica medieval del yacimiento de Cercadilla, Córdoba. Materiales emirales". IV Congreso de Arqueología Medieval Española. T.III. Alicante: 771-778.

GÓMEZ, S.(1993): “La cerámica verde y morado de Mértola (Portugal). Arqueologia Medieval-3:113-132.

KIRCHNER, H. ( 1986): “Les safes dels estrats II i III de Shadhafilah”. I Congreso de Arqueología Medieval Española T.IV, Huesca 1985: 149-192.

LAFUENTE, P. (1994): "Cerámica islámica en el área suroccidental de Andalucía”. Arqueología en el entorno del Bajo Guadiana. Huelva: 565-583.

LEVI PROVENÇAL, E. (1953) "Description de l'Espagne d’Ahmad al-Razí. Essai de reconstitution de l'original arabe et traduction française", por E. Leví Provençal. Al-Andalus XVIII:. 51-108.

LÓPEZ, J.J. y otros (1988): “ Repoblación medieval en el Puerto de Santa María” Revista de Arqueología $n^{\circ} 82: 34-43$. 
MATOS, J.L. de (1987): "Cerâmica muçulmana do Cerro da Vila". Actas do IV Congreso Internacional A cerâmica medieval no Mediterraneo occidental. Lisboa, . Mertola, 1991: 429-456.

MOTOS, E. 1991 El poblado medieval de "El Castillón" (Montefrío, Granada). Monográfica de Arte y Arqueología.

OLMO, L. (1986a): "Cerámica común de época hispanomusulmana en Niebla. II Coloquio de cerámica medieval en el Mediterráneo occidental. Toledo 1981: 135-139.

- (1986b):" Nuevos datos para el estudio del asentamiento hispanomusulmán de Mesas de Asta (Jerez de la Frontera, Cádiz)". Actas del I Congreso de Arqueología Medieval Española T IV. Huesca 1985: 229-242.

PÉREZ, A. y TABALES, M.A.. (1995): "Intervención arqueológica en el palacio de San Leandro. Sevilla". Anuario Arqueológico de Andalucía, t. III, 1992: 621.-639.

RETUERCE, M. y ZOZAYA, J. (1987): "Variantes y constante en la cerámica andalusî". IV Congreso Internacional A ceramica medieval no Meditarraneo occidental. Lisboa: 315-322.

ROSELLÓ, G. (1991): El nombre de las cosas en al-Andalus: una propuesta de terminología cerámica. Palma de Mallorca.

TORRES, C. (1987): (Catalogo) Cerâmica islâmica portuguesa. Fundaçâo Calouste Gulbenkian, 16-27 novembro 1987. Campo Arqueológico de Mértola n 28.

TORRES, C. y otros (1987): "Cerâmica islâmica de Mértola- proposta de cronologia e funcionalidade". Actas do IV Congreso Internacional A cerâmica medieval no Meditarraneo occidental. Lisboa: 497-536.

VALDÉS, F. (1986): “La cerámica de tipo verde y manganeso: aparición, difusión y primeras influencias”. I Congreso de Arqueología Medieval Española. T.IV. Huesca 1985: 269-281.

VARELA, M. y VARELA, R. (1995): "Cerâmica muçulmana: quais as metodologias arqueológicas?" Actas das $1^{a}$ Jornadas de Cerâmica Medieval e Pós-Medieval, Tondela 1992: 41-50.

VIGUERA, Ma.J.(1992): Los reinos de taifas y las invasiones magrebíes. colecciones Mapfre, Al-Andalus 8. 

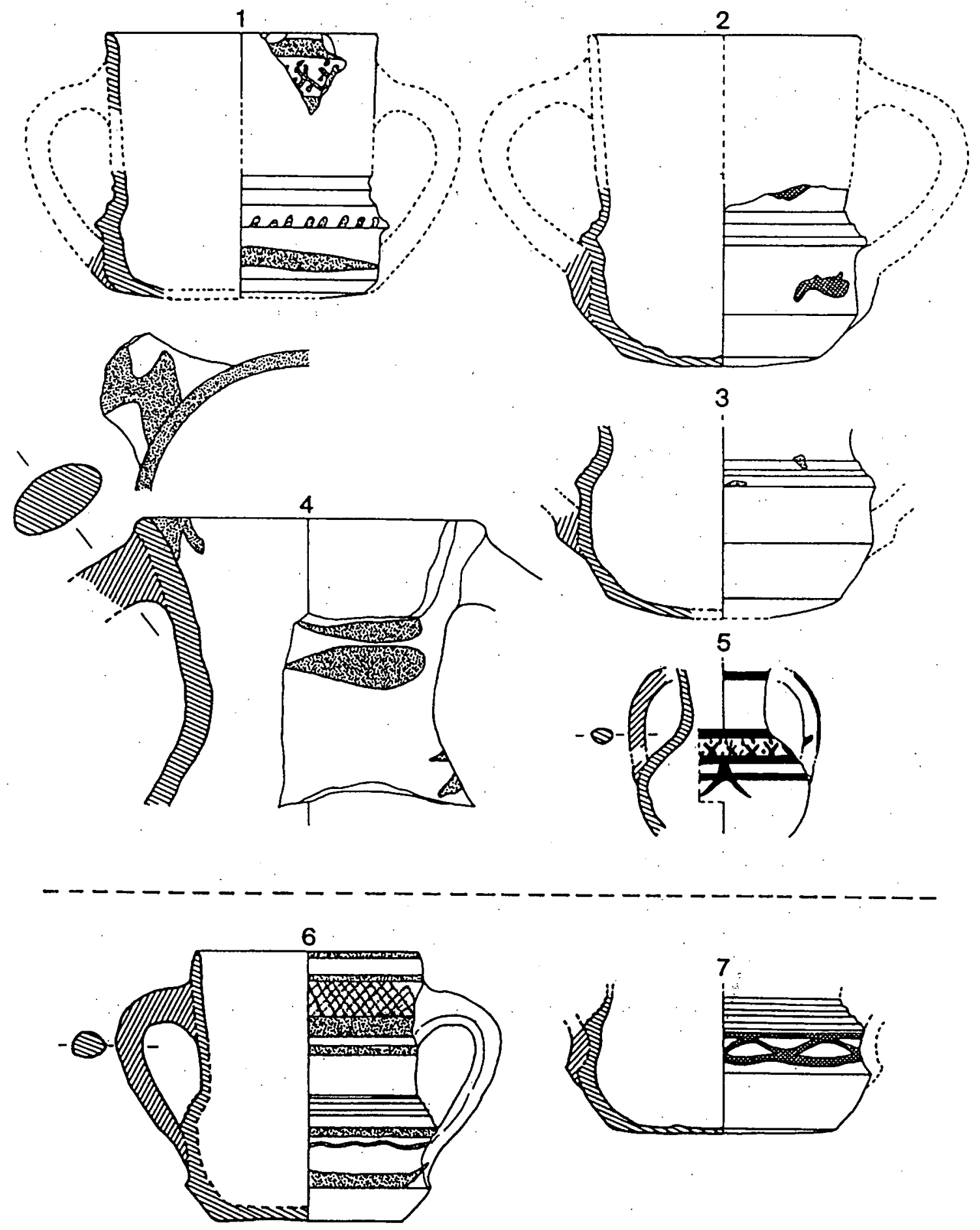

Fig.1

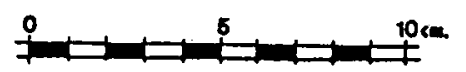

Figura 1: C/ Justicia $34\left(n^{\circ} 1\right.$ a 5 ), Museo Jerez (n' 6) y Mesas de Asta ( $\left.n^{\circ} 7\right)$ 

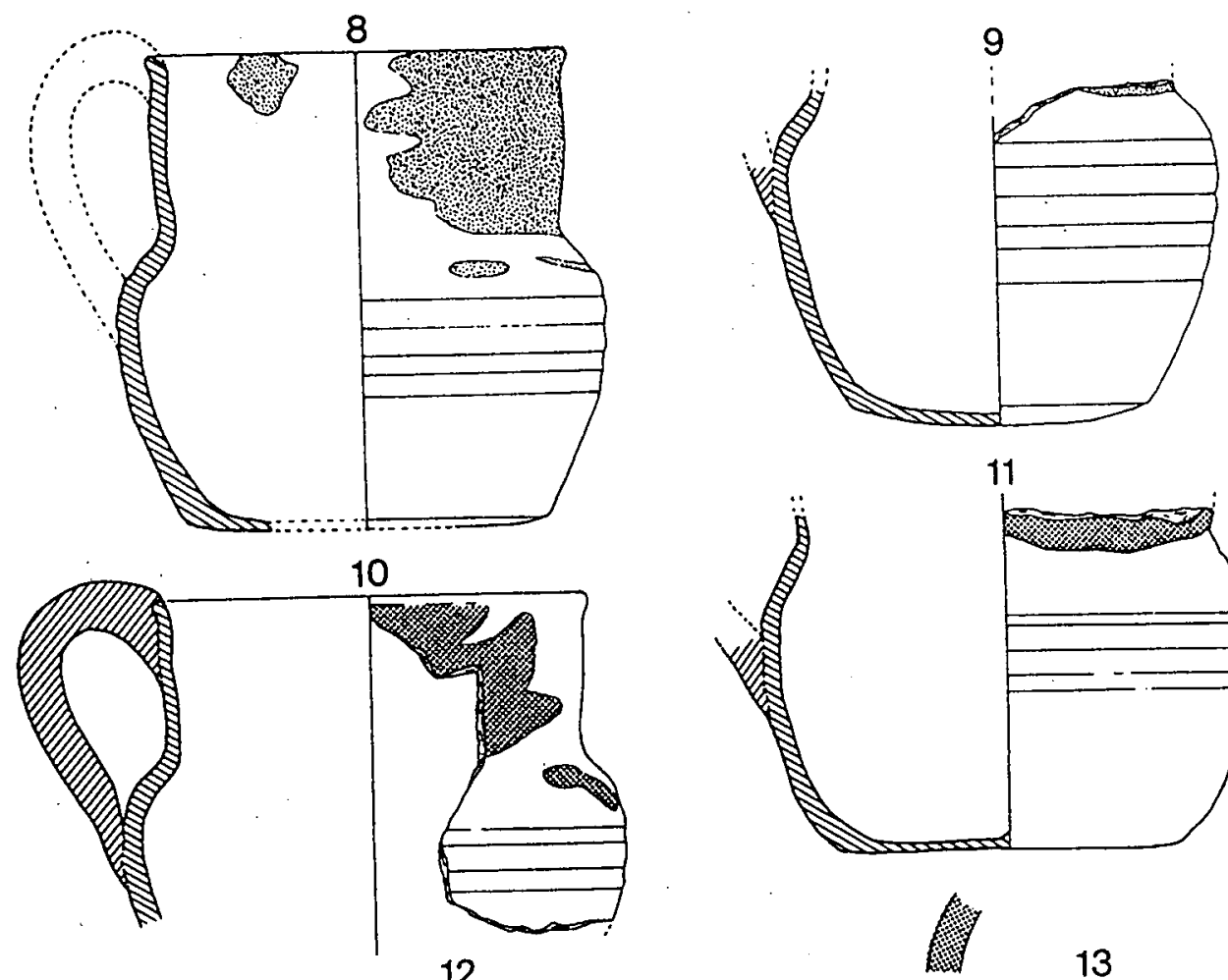

11
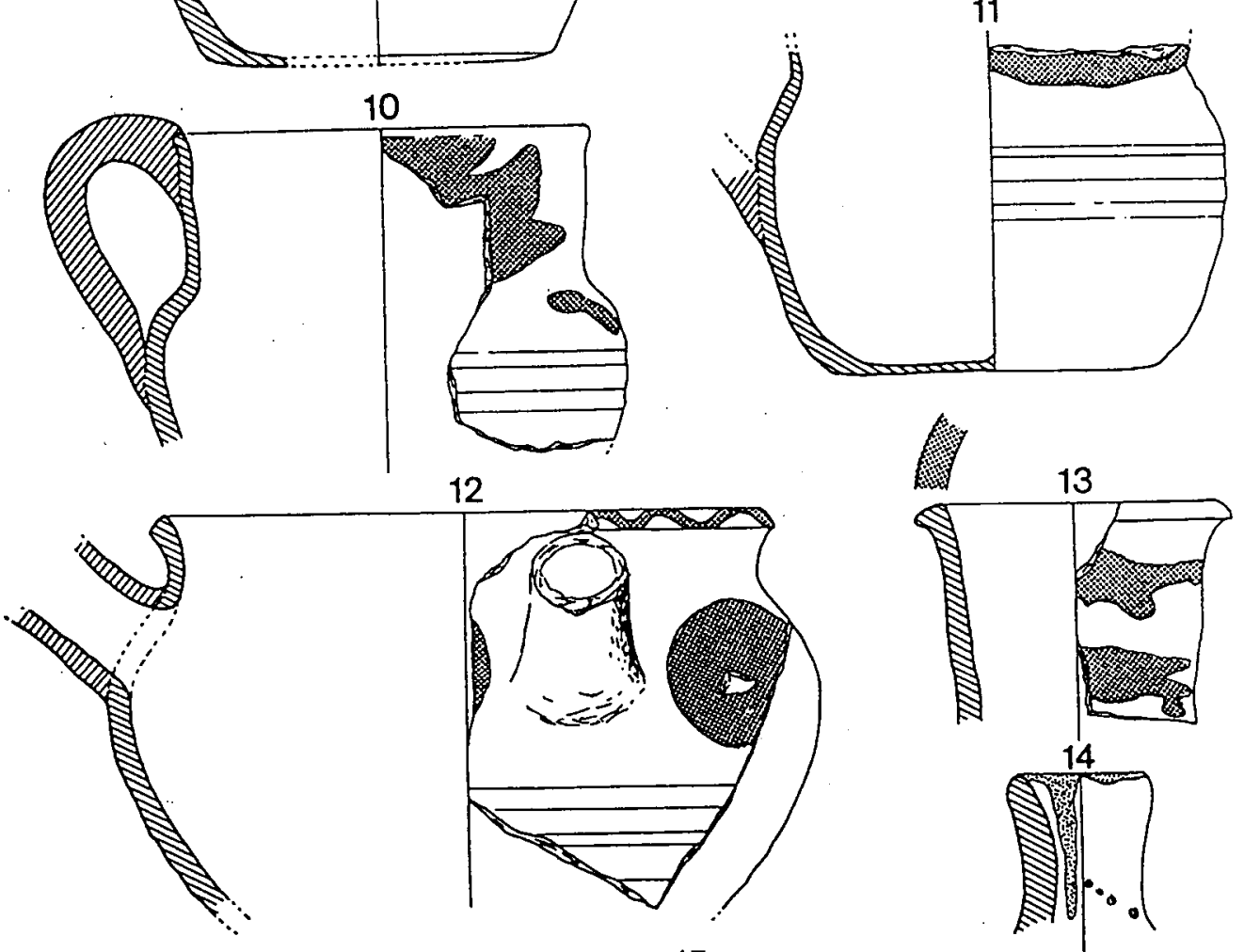

15

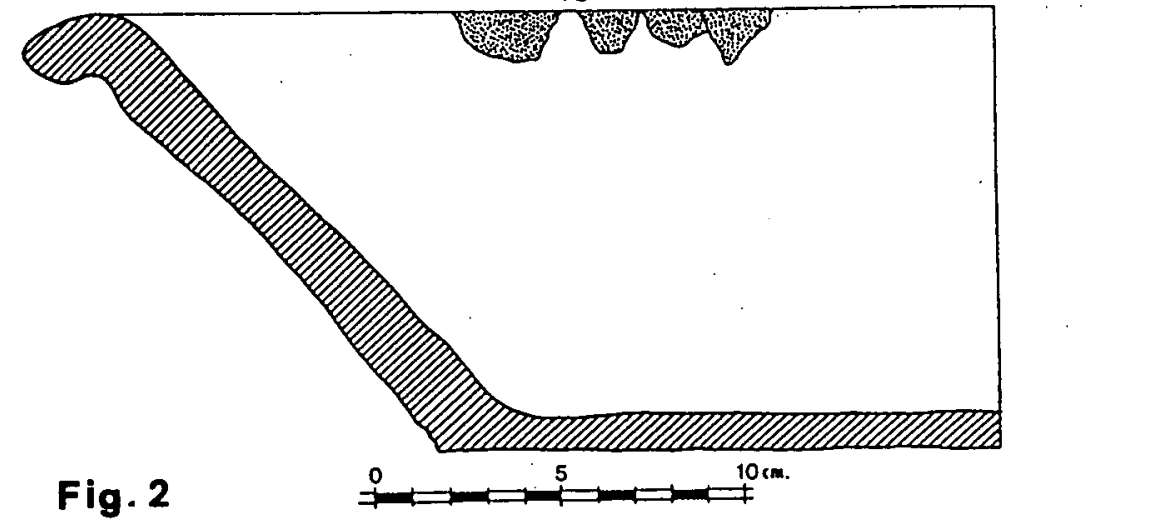

Figura 2: C/ Justicia 34 

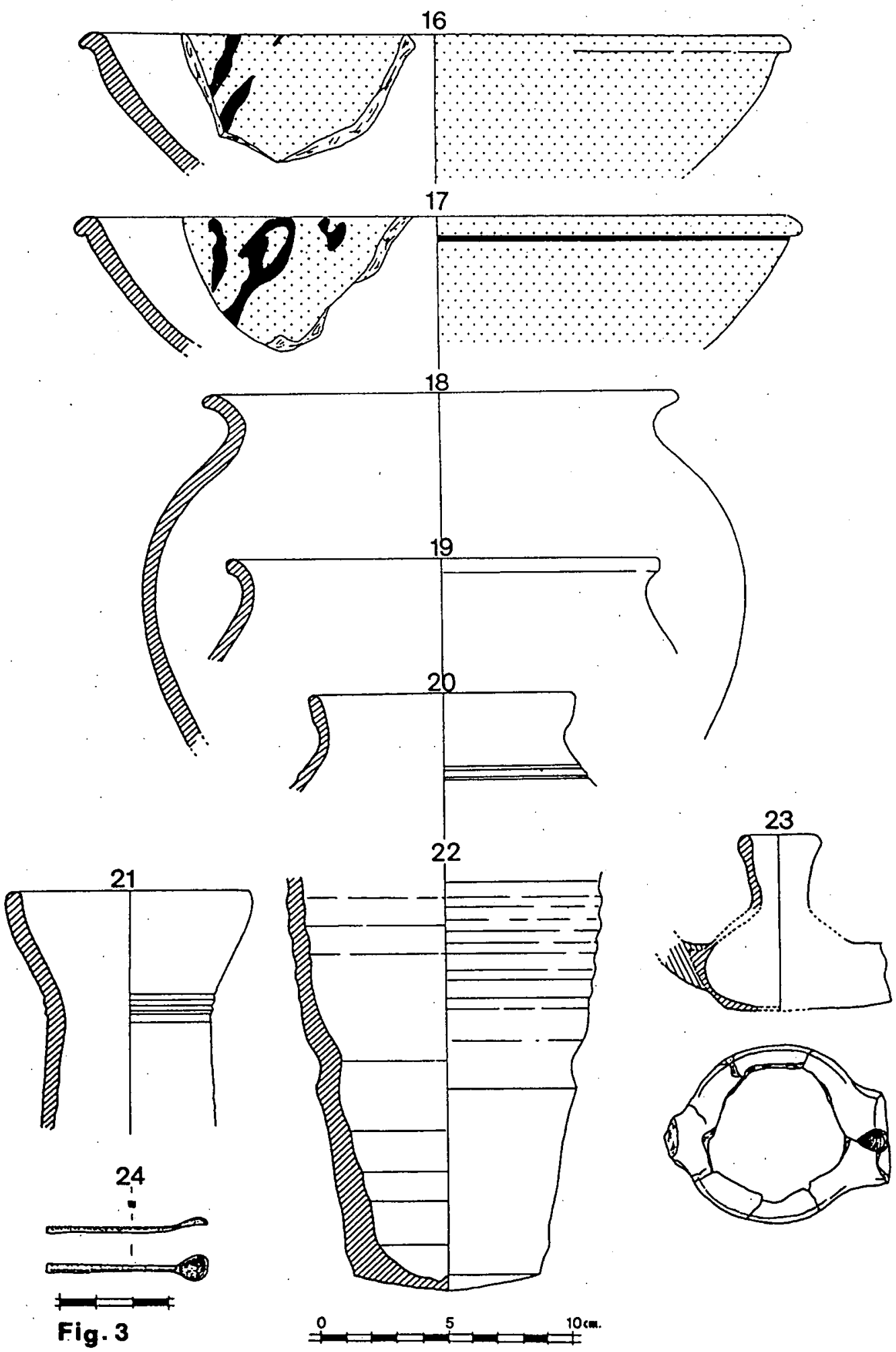

Figura 3: $\mathrm{C} /$ Justicia 34 

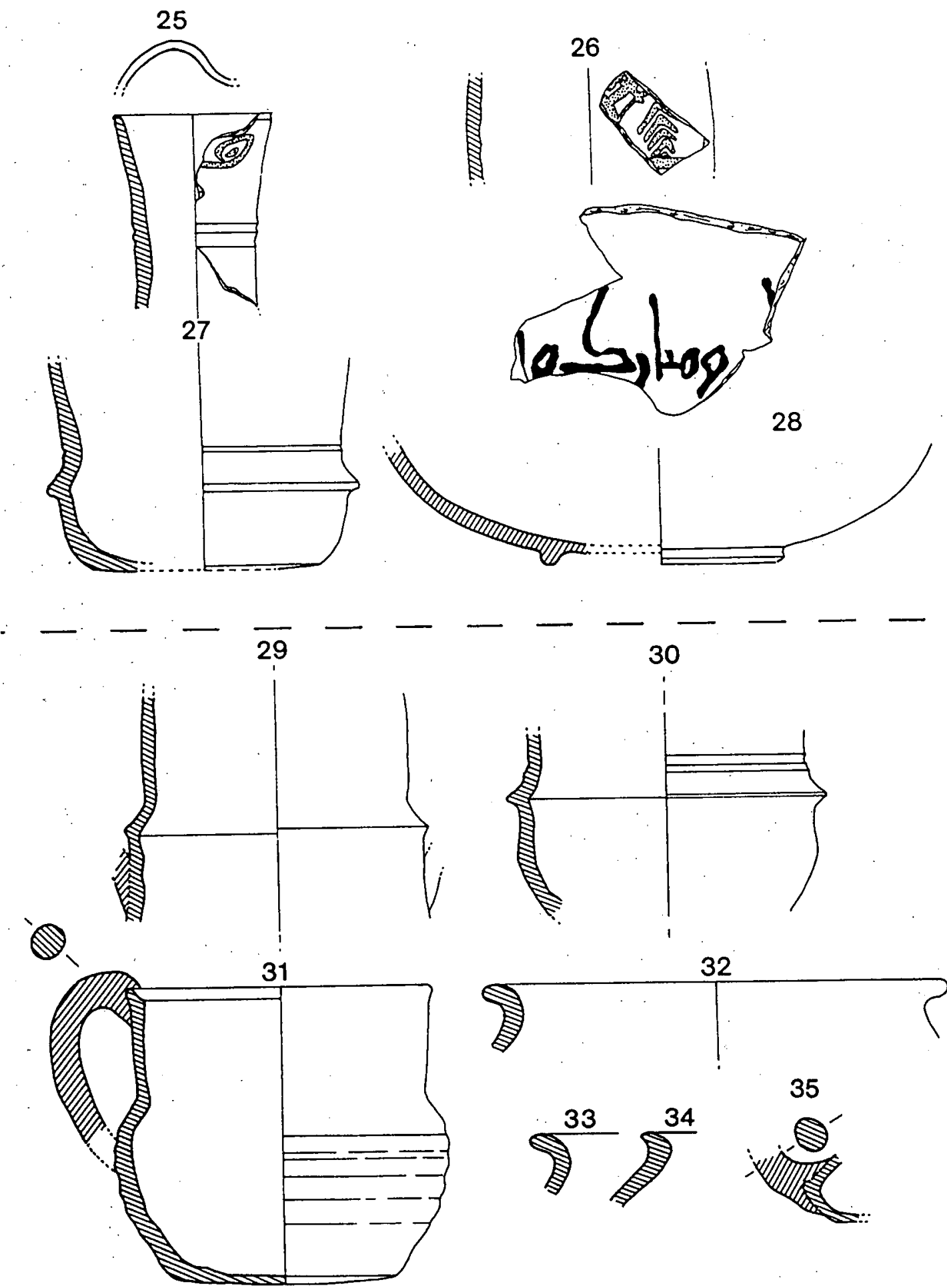

Fig. 4

Figura 4: Alcázar de Jerez . Palacio de Villavicencio. Pozo 5 ( nº 25 a 28), Pozo 7 (nº 29 a 35). 

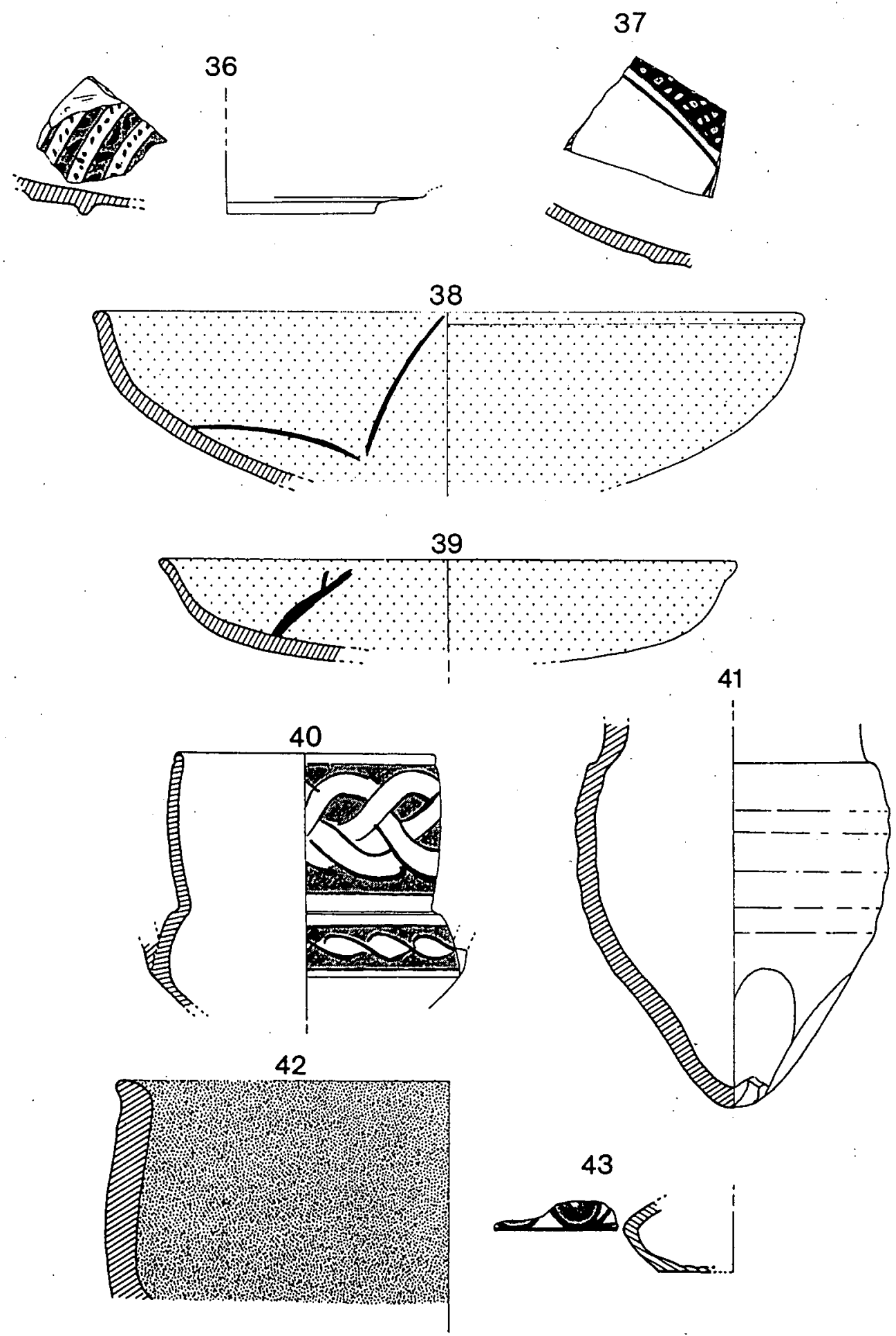

Fig. 5

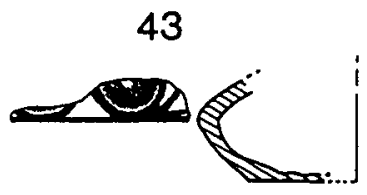

Figura 5: Alcázar de Jerez. Palacio de Villavicencio. Pozo 1. 